\title{
AVENTURAS (DES)FORMATIVAS NO AGENCIAMENTO DANÇARINO-CRIANÇA
}

\author{
Andrea Nascimento Elias ${ }^{\mathrm{i}}$
}

\begin{abstract}
Resumo: O texto problematiza os processos formativos na trajetória da Cia de Dança Teatro Xirê, que emergem da experiência de corpos postos em contato (de dançarinos e de crianças) mediados por uma linguagem que encontra na dança contemporânea sua possibilidade de existência. Tomando a ideia de vazio como categoria de experiência, o texto estabelece relações entre a ideia de vazio-pleno, proposta por Lygia Clark em sua obra, e a ideia de vazio encontrada num corpo feito "saco plástico" na obra "Dingling", criada pela Cia Xirê para crianças de 2 a 6 anos, evidenciando o projeto político (des)formativo presente na (des)pretensiosa tarefa de dançar para crianças quase bebês.
\end{abstract}

Palavras chave: Dança; Criança; Formação.

\section{(DE) FORMATIVE ADVENTURES IN CHILD-DANCER AGENCY}

\begin{abstract}
The text problematizes the formative processes that emerge from the experience of bodies in contact (of dancers and children) mediated by a language that finds in contemporary dance its possibility of existence. Taking the idea of emptiness as a category of experience, the text establishes relations between the idea of emptiness-full, proposed by Lygia Clark in her work, and the idea of emptiness found in a body made as "plastic bag" in the performance "Dingling", created by Cia Xirê for children from 2 to 6 years old, highlighting the (de) formative political project present in the (un)pretentious task of dancing for children almost babies.
\end{abstract}

Keywords: Dance; Child; Formation.

\section{A linguagem que se forma ao formar-nos}

A trajetória da Cia de Dança Teatro Xirêii foi impulsionada por um intenso desejo de aprender, mesmo que não fosse claro para seus integrantes o que aprenderiam para chegar onde pretendiam. Havia, no início daquela trajetória, o impulso desejoso de aprender a comunicar com o corpo em movimento de modo que este prescindisse de tradução em qualquer outro signo. "O que o corpo pode dizer por si mesmo?" era a pergunta deflagadora. Para atingir seu objetivo, o

2020 Bargas; Ayoub; Assaritti, Scarazzatto, Assis. Este é um artigo de acesso aberto distribuído sob os termos da Licença Creative Commons Atribuição Não ComercialCompartilha Igual (CC BY-NC-4.0), que permite uso, distribuição e reprodução para fins não comerciais, com a citação dos autores e da fonte original e sob a mesma licença 
primeiro ímpeto da criadora da Cia Xirê, Andrea Elias - recém-formada bailarina pelo Centro de Estudos do Movimento e Artes Angel Vianna, foi investir no encontro com aqueles que ainda não tinham se apropriado da linguagem verbal, ou que ainda possuíam pouca intimidade com os demais códigos sociais, fossem eles quais fossem. A ideia inicial da pesquisa da Cia era que, se era preciso aprender a comunicar com o corpo, e somente pelo o que o corpo é capaz de comunicar, então, poderiam ajudá-los crianças que ainda não falassem ou que ainda tivessem seu corpo como principal meio de expressão e comunicação. E, na indiscernibilidade conceitual do que estava sendo proposto - se o que se estava fazendo inseria-se no campo do Teatro ou da Dança - a Cia Xirê se engajou na tarefa de aprender a dizer com o corpo em movimento dirigindo-se a bebês e crianças ainda em processo de constituição da linguagem verbal.

Impulsionados e movidos por um desejo, foi no encontro com o olhar de crianças que uma articulação de linguagem se fez possível entre aqueles que propunham a situação cênica: dançarinos, e aqueles aos quais se pretendia espectadores: crianças. Do engendramento dessa articulação de linguagem uma poética se foi constituindo ao longo dos anos, não à priori, portanto, mas em experiência.

Na entrada do século XXI, sem referênciais disponíveis no que concernisse à relação com crianças por meio do corpo em movimento nos mesmos propósitos que os seus e na aridez do campo teórico sobre os fenômenos do corpo que dança, foi no olhar do outro que o projeto coreográfico da Cia de Dança Teatro Xirê se organizou ao longo dos anos.

Já na fase inicial da Cia Xirê, mesmo que não se soubesse identificar em qual linguagem artística se inseria, buscava-se que o sentido primeiro do que viria a se chamar de dança pudesse ser lido no próprio corpo que a gera e que nela se gera, e que a intenção, clara ou obscura, do ato poético passasse pelo movimento como processo gerador, e pelos estados do corpo e do pensamento (LOUPPE, 2012, p. 47), o que, segundo Louppe, é elemento constituinte da poética da dança contemporânea. Mas, como chegariam a isso dançando para crianças como público? Aqui se recorta um contexto significativo ao qual o projeto de linguagem da Cia de Dança Teatro Xirê esteve conectado desde o princípio e que agora buscamos evidenciar.

Tratava-se, portanto, de um projeto de constituição de linguagem artística que se impunha a tarefa de comunicar com um público formado por crianças de até, no máximo, sete anos de idade. Mesmo que ainda não estivesse claro onde se inseria a produção artística da Cia Xirê, o engenho pretendido com o público formado por crianças tão pequenas nunca foi o de sua participação direta, convidando-os ao palco, por exemplo, ainda que sempre se corra o risco que 
isto aconteça pelo impulso espontâneo e imprevisível das crianças. As performances da Cia, aliás, se colocam sob esse risco intencionalmente. O que se pretendia era que as crianças se engajassem como audiência, de modo ativo e convocado pelos acontecimentos cênicos, mas sempre em situação de audiência. O desafio era que as crianças engajassem seus corpos como pensamento na aventura ali proposta. Mas o que e como propor a crianças tão jovens de modo que fosse possível para elas seguir uma linha de pensamento do corpo, acedendo à obra a partir de seus próprios recursos de elaboração?

A questão que se interpunha para a Cia neste primeiro instante, e que viria a orientar seus procedimentos poéticos dali para adiante, era, portanto, como estar com crianças tão pequenas, tendo como principal mídia o corpo, e compartilhar com elas uma reflexão. Reflexão esta gerada, vivenciada, experimentada e compartilhada pelo corpo em movimento.

Nesse primeiro momento de investigação artística, que durou em torno de cinco anos (mais precisamente de 1998, quando começou a criação do espetáculo "Ciranda: dança-teatro para crianças", até 2003, quando a Cia foi fundada), as intensas experimentações ${ }^{\mathrm{iii}}$ procuravam criar esse corpo necessário para conectar o olhar das crianças e (des)pretensiosamente seus pensamentos. Tais experimentos envolviam também o histórico da diretora Andrea Elias como educadora, o que permitia acesso a diferentes grupos de crianças, em diferentes situações e instituições, facilitando muito o acesso a esses grupos.

O trabalho com objetos foi um dos primeiros recursos encontrados para criar um elo entre o corpo do dançarino e o corpo desse público específico, e foi o recurso que possibilitou transitar o gesto concreto para a abstração do gesto dançando ${ }^{\text {iv }}$.

A introdução de objetos como elementos de construção poética também tem origem nas práticas somáticas, intensamente apreendidas pela diretora e coreógrafa Andrea Elias em sua formação como bailarina na escola fundada e dirigida por Angel Vianna ${ }^{v}$. Aos poucos, os objetos utilizados na sensibilização do corpo dos dançarinos e na abertura a novas percepções, tais como bolas, bambus, lenços, entre tantos outros - incluindo brinquedos elaborados para as infâncias foram sendo utilizados como parceiros nas improvisações dançadas. Ali, não era o que se fazia com os objetos o que importava, mas o que os corpos dos dançarinos produziam na relação com eles.

A relação dos corpos com os objetos introduz na pesquisa da Cia o exercício de equivalência entre corpos, salvaguardadas suas respectivas naturezas, até se chegar ao Contato Improvisação $^{\text {vi }}$. Menos que a intervenção de um corpo sobre o objeto, era já numa perspectiva de 2020: "Bebês e crianças: cultura, linguagem e políticas" 


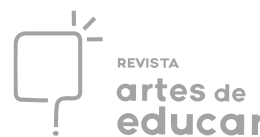

fenomenológica que o exercício se fazia ao permitir que o objeto também tocasse o corpo do bailarino com sua forma, cor, textura, odor, intervenção no espaço. $\mathrm{O}$ ensaio com objetos, nessa primeira instância da pesquisa, contribuiu fortemente para uma maleabilidade na plasticidade do corpo que seria transferida futuramente para a relação com o público de crianças. Note-se como aqui se ensaia o exercício de compreender o outro como parte (nesse caso o objeto inanimado), o que seria o desafio da Cia no exercício de aprender em encontro com o olhar do outro (agora as crianças).

Durante a pesquisa artística, a cada acesso entre objeto e corpo uma infinidade de possibilidades se desvendava, desde as ações mais concretas até a total virtualização do objeto fazendo com que ele desaparecesse, ficando-se apenas com a fabulação por ele despertada no corpo do dançarino. A fabulação refere-se, aqui, ao que remanesce no corpo depois que o objeto concreto é suprimido da experiência, ou mesmo quando permanece sem que sua funcionalidade seja evidenciada. No corpo resta a memória do objeto e da ação por ele suscitada, não há nenhuma história a ser contada embora sobreviva um rastro de narrativa, percursos, ritmos, intensidades, temporalidades. Os exercícios com objetos possibilitaram a assimilação de gestos, jogos e experiências concretas que fazem parte do universo da criança naquela fase de desenvolvimento do público pretendido pela Cia. A partir do gesto concreto acedia-se ao gesto abstrato trazendo com ele o olhar da criança.

A necessidade de referenciar o gesto abstrato em seu gesto concreto originário foi dada exclusivamente pelo contato com o público dessa faixa etária até os sete anos e tem sido o caminho por meio do qual a Cia tem feito a transposição do olhar da criança até o empreendimento da dança contemporânea. De modo simplificado, a operação se dá pela seguinte equação: parte-se de um gesto de possível identificação para a criança que, colando nele seu olhar, carrega consigo o engajamento de seu próprio corpo e com ele o pensamento até um espaço de fruição cinestésica onde lhe seja possível dispensar o retorno objetivo às operações concretas. Mas o que se revela ainda mais interessante é que, nessa dinâmica, não é apenas o olhar da criança que vem com o dançarino. O que ocorre aí é um complexo entrelaçamento de forças onde o dançarino também é capturado e transformado pelo olhar da criança, pois como dito acima, não se trata de um corpo agindo sobre outro.

Ainda que jogando com referenciais simbólicos comumente reconhecíveis - o que vem sendo proposto ao longo desses anos na prática da Cia Xirê, partindo de uma ação ou imagem reconhecível ao olhar da criança, não para conformá-la ou fixá-la, mas para desdobrá-la ou 
multiplicá-la, pressionando-a igualmente ao movimento, ou, quem sabe, a "uma dança" - é chacoalhar a percepção da dimensão concreta e tangível do movimento, numa dinâmica de ir e vir, de contenção e expansão, coletando, pelas variações produzidas na extensão, os pontos de apoio para a entrada no imaginário, sempre referenciados pela concretude perceptiva.

O engenho necessário nas experimentações da Cia era arrastar o gesto concreto até sua abstração em gesto dançado, ficando apenas com um rastro de concretude - regulado também pela percepção no ato da cena - capaz de manter o olhar curioso daquele que não precisa entender, mas ao qual se precisa manter conectado todo o tempo. $\mathrm{O}$ artifício inverso também tem sido engenho valoroso nas buscas da Cia Xirê, pressionando, desta vez, o gesto abstrato da dança até que ele possa tocar um fio ou um ponto de concretude onde o olhar das crianças possa embarcar. Por esse fio, ou ponto, tomar esse olhar em parceria e seguir com ele em conexão transformando a concretude do fio, ou ponto, enquanto se transforma o movimento. O ponto de embarque de olhares de crianças é conectividade, não é fixidez.

Desse modo, se a dança procura trabalhar fora da transmissão de um vocabulário pela imitação de um mestre que 'mostra', ela propõe a questão de uma linguagem que diz sem mostrar (BARDET, 2014, p. 238). E, interrogando sobre que língua poderia conduzir a linguagem ao limite de sua impossibilidade, estabelecendo ainda assim uma relação através das palavras com as sensações e os movimentos, Bardet nos conduz pela mão revelando-nos outro procedimento próprio à rotina na sala de trabalho da Cia Xirê durante a preparação de seus dançarinos:

Por exemplo, o trabalho de formação, de aquecimento ou de criação na dança que pretende não passar - somente - pela imitação de um modelo, inclui quase sempre algumas técnicas somáticas, das quais a epistemologia é quem sustenta a prática, onde nada é "mostrado", apresenta numerosas questões na relação com as sensações, os movimentos e as palavras. Uma relação, uma articulação, que busca, às apalpadelas, naquilo que continua escapar - parcialmente? - à ilustração, à referência, à ordem, através da "palavra de ordem", um esforço de atenção, que atravessa o movimento por sensações e imagens. Uma língua diretamente sobre o movimento que, por seu ritmo, seus alentos e seus sons, tece os sentidos das corporeidades em curso, e (se) articula as imagens (BARDET, 2014, p. 238-239).

Escapar à palavra de ordem e formar dançarinos. À primeira vista, essas podem parecer também orientações dissonantes. Embora seja claro no discurso, manter o foco de atenção em movimento requer também, muitas vezes, uma plasticidade frente às coisas do mundo que, implicando a corporeidade, é tarefa laboriosa. Mesmo quando se procura realizá-la com prazer e 


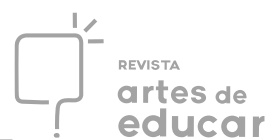

jocosidade há que se ter disposição: "O trabalho era árduo, muito árduo". Em entrevista ${ }^{\text {vii }}$ Tiago Quites e Luísa Pitta, ambos integrantes da Cia Xirê em períodos distintos, utilizam exatamente a mesma frase para se referirem à rotina de trabalho na Cia. $\mathrm{Na}$ insistência sobre o que era tão penoso, ambos se referem novamente à rotina diária de trabalho físico sim, mas que os convocava, igualmente, à tomada de posições a todo instante. As tomadas de posição física encontram, no trabalho da Cia Xirê, tomadas de posição subjetivas, de opinião, de argumentação, de percepções do mundo que articulam imagens produtoras de movimento. Formar, nesse caso, não encerra uma forma, mas dispõe a corporeidade para sua indeterminação, para sua (des)formação ou, em outras palavras, para a sua permanente plasticidade.

\section{Não-saber, não-querer, não-poder: um vazio como categoria de experiência}

Em A Educação para Além do Capital, István Mészáros (2008) lembra que somente pelo trabalho é possível superar a alienação com uma reestruturação radical de nossas condições de existência há muito estabelecidas e, por conseguinte, de 'toda a nossa maneira de ser' (p. 60. destaques do autor).

Nesse processo formativo empreendido na Cia Xirê, onde a percepção sensível é potencializada, constituído nesse jogo interrelacional entre corpos, o convite ao questionamento "Como me posiciono diante do outro?" junto a suas implicações, ecoa continuamente. Essa atitude autorreflexiva confronta e faz pensar a constituição e destituição de um "si mesmo", sendo sempre a relação com o outro a medida desse sujeito. Nessa vivência, as articulações entre atuação (modos de estar em cena ou em sala de trabalho) e subjetividade, transfiguram-se, em "trabalho sobre si”, que, nas palavras de Carla Andrea Lima, constituem um conjunto de práticas onde a ideia mesmo de "si" é problematizada colocando a corporeidade advinda dessas práticas como algo a ser colocado em perspectiva (LIMA, 2014, p. 155).

A tarefa de reestruturar radicalmente o ser como proposta de superação da alienação, como sugere Mészáros (2008), vem sendo empreendida ao longo dos anos, pela Cia Xirê, associada a uma proposição da relação dos conceitos de corpo e espaço como sugere Godard (2010). Agenciar de novo e novamente, a partir de cada encontro, as histórias particulares e os modos perceptivos das dinâmicas espaciais que aprisionam o corpo (GODARD, 2010), eis aqui o que, hoje, suspeito ser o que torne o trabalho da Cia uma atividade intensiva e significativa para quem a experimenta. No estar em cena, a experiência do sentir estar no mundo é 


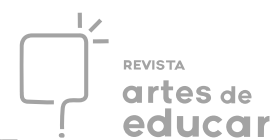

confrontada. Encarando a tarefa de olhar e ser olhado o que acontece em cena emerge como abertura e des-subjetivação, lugares sem lugar no espaço da política (IKEOKA, 2016, p. 134). A ideia de recriação de subjetividade que se manifesta aqui, embora venha acompanhando a Cia subliminarmente desde o primeiro momento em que se fala em ser com o outro, encontra-se, no exercício de reflexão sobre esta prática, com a ideia de vazio.

Para seguir pensando sobre a ideia de vazio como um exercício de recriação de subjetividade integrante da experiência formativa na prática de dançar a partir do olhar de crianças, tomemos como partner o trabalho de Lygia Clark, mais precisamente a obra Saco Plástico Vazio ${ }^{\text {viii }}$. A potência poética de um saco vazio toca, com intimidade, a memória revelada das vivências artísticas/pessoais de Andrea Elias, como performer, na obra "Dinglingix", a qual me referirei a partir de agora. Ali, a performer era o saco vazio!

O que significa, então, essa aproximação da experiência da performer, nessa obra, com a imagem de um saco vazio? E, sobretudo, como a ideia se relaciona com a experiência de recriação de subjetividade? E, ainda, como essa experiência se constitui formadora?

A partir das vivências no citado trabalho da Cia de Dança Teatro Xirê, passo a discorrer sobre a ideia de um vazio, cuja consistência possibilita ao saco parar de pé também, e até dançar, permitindo-me ao trocadilho com o dito popular que diz que "saco vazio não para em pé". Ao cercar a ideia desse vazio pretendo apontar como, na prática da Cia, ele se manifesta e o que ele manifesta quando se faz acontecimento em situação cênica, estabelecendo relações com a preparação e consequente aventura (des)formadora que atravessa a trajetória da Cia e pautando, por fim (ou por princípio), suas implicações políticas.

Como descrito até aqui, a inquietação que move as pesquisas da Cia Xirê desde sua criação carrega, em sua gênese, a confrontação com o outro, pois foi no encontro com o olhar do outro que se foi construindo um projeto cênico orientado pelas variações de intensidades produzidas nesse encontro direto com o público, expressivamente formado por crianças. Assim, a proposição estética da Cia de Dança Teatro Xirê foi sempre pautada na dimensão de recriação da existência nesse limiar eu-outro. Proposições estética e ética foram, desse modo, caminhando juntas desde o princípio.

Na entrevista "A Ética do Cuidado de Si como Prática da Liberdade”, Foucault (2004) discorre sobre os modos ativos de constituição do sujeito por meio de práticas de si. No entanto, seguindo o raciocínio do autor, essas práticas não seriam inventadas pelo sujeito, mas esquemas que lhes são propostos, sugeridos, impostos pelas relações sociais. A tarefa criativa de resistência 
às imposições desses esquemas estaria em resistir aos modos como eles nos assujeitam, investigando, como sugere Foucault, não somente aquilo que se é mas, e principalmente, interrogando-se sobre o que não se é.

No capítulo "Além do dilema de Hamlet: ser e não ser" (ELIAS, 2008), ao discorrer sobre a relação que existe no desafio proposto ao artista cênico (ator, dançarino ou performer) de desprender-se de si mesmo, a figura de Hamlet é abordada para revelar a dimensão trágica que o momento representa. Segundo a autora e em conformidade também com Oida (2001), este seria um momento crucial para o artista cênico, no qual ele é colocado diante da possibilidade de liberar-se de um "si mesmo", desprendendo-se, assim, do que comumente nominamos identidade pessoal, podendo fazer a escolha, em sua prática artística, de permitir-se ser atravessado, ou mesmo de "deixar de existir", corroborando com um modo de ser no mundo que lhe permita ser e não ser, ser múltiplo (ELIAS, 2008, p. 98). Como sugere o título do capítulo, na aventura de existir é preciso haver certa predisposição para a morte. Poderia-se dizer que, mais do que uma predisposição, é preciso que haja engajamento, muitas vezes duro, para, em situação cênica, colocar-se na margem, à beira do salto no vazio que nos destitui de nós mesmos. Ainda no mesmo capítulo Elias desenvolve como as dinâmicas paradoxais do movimento possibilitam essa experiência de multiplicação do sujeito e, nesse processo, uma inevitável confrontação com a morte, com a "destituição de si".

Em linhas gerais, a dimensão paradoxal do movimento seria uma dinâmica de forças resultante de um direcionamento preciso e multifocal da atenção durante sua realização, ampliando seu espaço de ação e alterando, nessa dinamização de forças, a percepção dos limites do corpo, provocando uma espécie de diluição desses limites. Ativando um feixe de forças musculares, em determinada qualidade de atenção, o corpo treinado seria capaz de dinamizar o movimento mantendo-o ativo na musculatura mesmo quando não visto a olho nu e, nesse processo de virtualização, ser capaz de "ampliar" ou "diminuir" os limites do próprio corpo. Essa diluição dos limites do corpo possibilitaria a coexistência deste com os demais elementos ao redor, fundando um espaço de relação em Estado Cênico, onde as identidades se embaçam, não se perdem, nem deixam de existir, mas passam a coexistir. Assim, o atuador - ator, bailarino, performer - precisa confrontar-se com a potência de existir além (ou aquém) de um "si mesmo", descobrindo-se em multiplicidade (ELIAS, 2008, p. 92-93).

Deflagrado pela materialidade dos corpos, esse espaço paradoxal não se situa em nenhum corpo, mas, ainda que fundado nas materialidades corpóreas envolvidas nessa dinamização de de 2020: "Bebês e crianças: cultura, linguagem e políticas" 


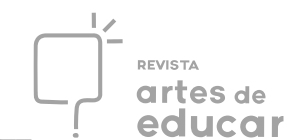

forças, e dependente delas, é um espaço que se erige no entre. Virtualidade produzida por circuitos em relação promovendo um looping dos registros dentro e fora, eu e outro, pensar e agir (ELIAS, 2008, p. 94). Essa abordagem encontra-se com a de viés psicanalítico no artigo de Carla Andrea Lima (2014, p. 163), que, seguindo a teoria lacaniana ao perseguir a ideia de um corpo estranho e ao mesmo tempo entranho ao corpo objetivo (virtual do corpo?) conclui:

Trata-se então de investir numa escuta que possa suportar o paradoxo, sustentado-se nessa zona de opacidade corporal. Assim, cabe ao ator-bailarino ampliar a escuta para essas bordas que se fazem entre memória e corpo, entre eu e outro, entre imagem e aquilo que nos convoca como fora/dentro da imagem. Nesse espaçamento, o corpo trabalha ativamente sobre o sujeito, esboçando formas, contornos, ações variadas. Esboços que exercitam e clareiam o traço e o caminho na medida mesma em que o corpo o faz e o refaz (LIMA, 2014, p. 163).

Gostaria de evidenciar nesse "trabalho sobre si" o esforço demandado de um "si mesmo" (ator-dançarino-performer) em sua reiterativa destituição na prática artística proposta na Cia Xirê. O que saliento aqui é o fato de ser sempre proposição de um "si mesmo" (e muitas vezes trabalho, engajamento, em conformidade com Mészáros anteriormente citado) lançar-se ou não no vazio. Lançar-se no vazio, encarar a morte nesse processo de reinvenção de existência, é uma resposta da vida às insistências do poder sobre ela. O risco é sempre iminente, está sempre lá, e dribrá-lo ou dobrá-lo é escolha e, em alguma medida, esforço de resistência de uma subjetividade face aos esquemas a ela propostos. No caso da Cia Xirê, que responde ao mundo propositadamente pelo corpo agenciado por crianças, esse empreendimento de esforço é encarado em sua fisicalidade, em primeira instância, cabendo considerar o corpo em sua configuração sistêmica como sugere Hubert Godard ao condenar a visão de corpo como instrumento a ser dominado e controlado antes de um interesse pela relação deste com seus processos de sentir, que são também processos políticos na medida em que relacionam o indivíduo com seu contexto. Quando compreendemos o corpo sistemicamente, incluindo aí sua dimensão sensível, aceitamos a impressão carnal da dimensão política da existência.

Em artigo sobre a hibridação arte-vida na obra de Lygia Clark, Suely Rolnik descreve a articulação entre estética e ética no processo de recriação de existência que se radicaliza ao longo da trajetória da artista, sobretudo na fase que se inicia com a obra Caminhando, de 1963. Escreve Rolnik: O que Lygia quer é que o festim do entrelaçamento da vida e da morte extrapole a fronteira da arte e se espalhe pela existência afora. E procura soluções para que o próprio objeto tenha o poder de promover esse desconfinamento (ROLNIK, 2003, p. 3).

Revista Interinstitucional Artes de Educar. Rio de Janeiro, V. 6, N.2- pág. 748-764 maio-agosto de 2020: "Bebês e crianças: cultura, linguagem e políticas"

DOI: $10.12957 /$ riae.2020.46224 
Situando ainda como marco a fase Caminhando, em artigo posterior Rolnik descreve como Lygia Clark - a quem ela define: a artista - ultrapassa um limite de sua obra. Rolnik destaca como a materialidade da obra de arte reflete o processo que atravessa a artista: a transição do plano ao relevo e daí para o espaço até se voltar para o espectador. A obra migra, segue Rolnik, do ato ao corpo e a partir daí Lygia Clark traça uma trajetória original, considerando as propostas de arte não apenas de sua época, mas mesmo para os tempos atuais. Ao dirigir-se à relação entre os corpos em sua obra, Clark mergulha na subjetividade, buscando estratégias que visam desentorpecer o corpo vibrátil ${ }^{x}$ do espectador para permitir que, liberto de sua prisão no visível, ele pudesse iniciar-se na experiência do vazio-pleno e aceder ao plano de imanência do mundo em sua misteriosa germinação (ROLNIK, 1999, p. 12).

Rolnik diz que a noção de "vazio-pleno" é cedo elaborada por Lygia Clark, acompanhando-a até o final de sua vida e se definiria como a experiência do corpo vibrátil toda vez em que se processa o esgotamento de uma cartografia, quando está se operando a silenciosa incubação de uma nova realidade sensível, manifestação da plenitude da vida em sua potência de diferenciação (ROLNIK, 1999, p. 6). Clark compreende que a experiência do vazio-pleno deve ser incorporada para que a existência possa ser vivida e recriada como obra de arte.

Na fase dos Objetos Relacionais, última da artista, onde objetos ordinários são vertidos a obras de arte a partir da relação do participante com a mesma, em sessões individuais que a própria artista organizava em um cômodo de sua casa, os sacos plásticos assumem diferentes funções e títulos de acordo com a relação criada com o objeto. Assim, sacos plásticos aparentemente iguais serão obras diferenciadas a partir da relação dos fruidores com esses objetos. Mas é ainda na fase anterior, das Arquiteturas Biológicas, onde encontramos Ovo Mortalha, que a experiência corpórea proposta na extensão entre corpo do participante e obra vai justificar o reconhecimento de uma proposição similar nas experiências com as obras da Cia Xirê, entre as quais tomamos "Dingling" para análise.

Mesmo sem ter havido nenhum contato com a obra de Lygia Clark durante a criação do espetáculo, as descrições dos processos com Ovo Mortalha grudam-se aos mesmos aspectos da obra "Dingling", propondo uma experiência muito similar à pretendida no espetáculo em questão.

$\mathrm{Na}$ descrição da própria Lygia Clark, Ovo Mortalha é feito de materiais vazios de significado que somente recobram a vida por meio do suporte humano. Lembrando que nessa arquitetura, o saco plástico transparente jaz sobre o pavimento, adquirindo vida somente a partir 


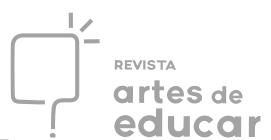

da interação entre os corpos que nele se abrigam ${ }^{x i}$. Na dimensão do visível a obra é uma estrutura flexível que se faz a partir da interação dos gestos dos participantes. Mas, em sua dimensão menos visível, contudo não menos concreta, a obra Ovo Mortalha propõe, em sua constituição, a dissolução do princípio identitário, onde a consistência das subjetividades dos participantes é posta em processo ao descobrirem-se não mais como individualidades, senão como efeito de um agenciamento coletivo. Nessa etapa, a obra de Clark depende do encontro entre os corpos e do que se passa neste acontecimento, bem como dos devires mobilizados de modo singular no corpo vibrátil de cada um. Deste modo, falar de identidade já não é mais possível, posto que esta é uma ideia incompatível com subjetividades que se constituem no processo dinâmico de plasmar-se, proposto pela obra (ROLINK, 1999, p. 16-18). Ainda nas palavras de Lygia Clark sobre Ovo Mortalha em carta endereçada a Helio Oiticica, o plástico transparente sem cor é quase como um ectoplasma que liga imaterialmente os corpos (ROLINK, 1999, p. 17).

Rolnik (1999) traça ainda, na trajetória de Clark, a transição da ideia de espectador de uma obra para a de fruidor participante. Tal transição se reflete na passagem de uma experiência de projeção que sublima os problemas como símbolos, figuras ou objetos constituídos (no caso do espectador da obra), para a experiência de receber as percepções em bruto, sem filtros, vivendo-as e elaborando-as por meio de processos que tanto podem regredir quanto crescer em relação com o mundo (no caso do fruidor participante):

O ritual que acompanha os objetos que Lygia nos propõe desde as Arquiteturas Biológicas até sua última obra é feito de atitudes, gestos e modos de corpos se comunicarem, estranhos aos hábitos e às significações práticas, os quais mediados por aqueles objetos criam as condições de uma intimidade compartilhada com o corpo vibrátil e a viagem de ida e volta à experiência do "vazio-pleno" (ROLNIK, 1999, p. 21).

De algum modo, as experiências propostas por "Dingling", espetáculo evocado para falarmos de um vazio que se constitui proposta formadora na Cia Xirê, propõe ritual semelhante. Lembrando que as buscas que originaram o projeto de linguagem da Cia baseavam-se nesse jogo interrelacional entre o ator-bailarino e o "olhar do outro", foi sempre nesse espaço intersticial que o trabalho se organizou e se orientou, o que significa dizer também que nele tantas vezes se desorganizou e se desorientou. Sempre um interrogar sobre um "si mesmo" a partir do olhar do outro. De algum modo, o "vazio-pleno" de Clark - essa experiência do corpo vibrátil no esgotamento de uma cartografia para o devir de uma nova realidade sensível promovida no encontro entre corpos que se comunicam, mediados por objetos que criam condições de uma 
intimidade compartilhada - foi, em alguma medida, experiência balizadora na construção de uma linguagem em dança. Considerando, claro, o corpo como mediador da experiência em dança, o que encontra ainda reverberação na obra de Clark, uma vez que ela migra a realização de sua obra do suporte material para o encontro e comunicação entre corpos.

O vazio, cuja ideia buscamos cercar para pensar sobre (des)formação no trabalho da Cia Xirê, não se refere exclusivamente a uma questão identitária, ao menos, não se fixa a ela. Não se trata de deixar de ser, mas de ser, por instantes, fora de si, de perder-se. Ao pensarmos sobre formação nesse processo, pretendemos cercar o que as interações nele promovidas têm produzido como formas de estar no mundo e, neste sentido, sendo educação apenas quando seja um processo estético.

O vazio não se constitui, portanto, como uma ausência, mas como uma proposição ativa que encerra esforço (tomado na medida de sua necessidade, não se referindo aqui a um "a mais", mas a um "necessário") e treinamento para entrar em empatia com o outro. Ora, se se trata de empatia, num primeiro momento a questão identitária é não apenas presente, mas fundamental, ela é porta de entrada, é o convite. Mas a identificação aqui não é simbólica, faz-se pela promoção de uma espécie de reconhecimento de vibração energética ${ }^{\text {xii }}$. E é por essa via que a identificação ocorre e uma fresta para brincar do lado de fora é aberta. A partir daí pode acontecer que tanto o performer quanto o outro se embacem, ou seja, que as identidades percam suas bases no campo virtual, posto que, na realidade objetiva a performer jamais deixa de ser ela mesma e o outro não deixa de ser o outro. Durante o acontecimento "Dingling", quem está na sala observa sempre a performer e o(s) outro(s). Mas quem está na sala também percebe uma conexão muito intensa entre a performer e os demais participantes (crianças igualmente performers?).

Para a criação de "Dingling", performance em dança contemporânea destinada ao compartilhamento com crianças de 2 a 6 anos, a Cia utilizou o material recolhido na pesquisa “Isto é sobre liberdade: o que você ainda lembra sobre ela?". Essa pesquisa foi apoiada pelo Fundo Iberescena e desenvolvida na cidade de Barcelona (Espanha) em junho de $2015^{\text {xiii }}$. Na pesquisa "sobre liberdade" os integrantes da Cia foram para as ruas pretendendo "esgarçar espaços para liberar fluxos".

As saídas à rua tinham sempre a intenção primeira que sempre moveu os empreendimentos da Cia: aprender. Se, na gênese, a Cia foi dançar para crianças para aprender com aqueles em idade pré-verbal a dizer sem dizer palavra, agora a tarefa se motivava pela 
necessidade de aprender a "praticar a liberdade". E, para tal investigação, Andrea Elias, na condição de performer, lançou-se à rua dispondo-se como o saco plástico vazio de Clark, com todos os riscos que isso representava, dispondo-se, no espaço urbano, organizada pelos materiais coreográficos que a estruturavam, à experiência do corpo vibrátil.

Neste exercício, muito valeu a base somática da preparação de Andrea Elias. Na rua, a performer buscava, então, manter desperta sua atenção para os sentidos, tanto quanto fosse possível. Nesse ambiente carregado de estímulos, a performer fazia em si a experiência de abrir espaços para a empatia cinestésica. Aguçando sua estesia e alargando sua percepção buscava estar atenta às mudanças que ocorriam também em seu corpo. Nas performances criadas durante a pesquisa "liberdade", Andrea Elias esgarçou a senso-percepção em ambiente urbano até onde pode. Aqui, a dançarina lançava mão da dinâmica do Contato Improvisação que integra a preparação dos bailarinos da Cia também desde muito cedo. O que se coloca em jogo na situação do CI é o desenvolvimento de uma capacidade de escuta e resposta a um ambiente movente. Foi a necessidade de disponibilizar os corpos a perceberem realidades flutuantes (GODARD e KUYPERS, 2010, p. 7) que trouxe o Contato Improvisação, em suas variadas proposições, para a preparação da Cia. Nesse contexto, a superfície-pele é expandida, território de fronteira onde irrompe a recriação virtual dos corpos (ELIAS, 2008, p. 137). O aguçamento da sensopercepção esgarçava a superfície-pele convertendo-a em malha porosa, espaços de vazamento subjetivo. Nessa operação, mais uma vez encontramos o vazio. $\mathrm{Na}$ ideia de vazar, escoar, em direção ao outro, a dançarina vai se "des-fazendo", se "des-formando".

Em "Dingling", no entanto, o processo de des-fazimento dá-se num procedimento bastante peculiar, uma vez que o engajamento se dá em direção a crianças muito jovens. A performance acontece sobre um tapete com uma área de cerca de $50 \mathrm{~m}^{2}$. Mais uma vez o público está próximo o suficiente para se lançar no movimento quando desejar. Nenhum convite direto é feito neste sentido. Há uma coreografia que, assim como na experiência da rua, fornece uma estrutura. Mas em "Dingling", crianças de 2 a 6 anos estão ao redor da dançarina, são bebês, muitas vezes. Como convocar a uma evasão de si àqueles que pouco, ou nada ainda, se compreendem "si mesmo"? A agulha magnética volta-se mais uma vez ao "trabalho sobre si". Ali, mais uma vez, a performer é o saco vazio! Ela não vê o que acontece ao seu redor nos primeiros sete minutos da performance, tem os olhos fechados e uma atenção sutil com a respiração. Conta com a superfície-pele expandida ao extremo e essa vibração esbarra naquelas (outras) que ali estão, tão vivas, vidas mais próximas de seus estados embrionários, onde a 
forma ainda não pegou inteiramente (PÉLBART, 2007, p. 63). A performer estabelece contato, e dança o contato sem sair da estrutura coreográfica que a situa ainda "si mesma", eles cá, ela ali. Escapa pelos poros da superfície-pele malha esgarçada. Ao, final, eles meio que "se misturam" a ela, porque afinal não se distinguem tão bem. Não há mais eles cá, ela ali.

Pássaros e leões nos habitam, diz Lygia - são nosso corpo-bicho. Corpo vibrátil, sensível aos efeitos da agitação de fluxos dos universos que nos atravessam a cada momento de nossa existência. Corpo-ovo, no qual germinam estados intensivos desconhecidos provocados pelas novas composições de sensações que os fluxos, passeando para cá e para lá, vão fazendo e desfazendo. (ROLNIK, 2003, p. 1)

Dançando o contato com aquela realidade movente e vibrante, "a performer-si mesmaestado coisa" só pode ir e ir e ir. Até que se vai mesmo, deixando o espaço sem fazer falta, porque vai, mas ainda está, vibrando nos corpos das crianças que nela vibram.

É somente restituindo o valor da experiência na Educação (LARROSA, 2017) que podemos considerar formativo o acontecimento que se dá no entrelaçamento dançarino-criançalinguagem. Essa tarefa de despossessão do sujeito (SAFATLE, 2016), empreendida na aventura de dançar para crianças, conforme proposta pela Cia Xirê, talvez nos oriente na impossível tarefa de reestabelecer novos circuitos de afetos. Aqui, um (des)pretensioso espetáculo de dança contemporânea para quase bebês, em sua tarefa de não ser nada além disso o que é, demonstra sua força política a cada vez que faz vibrar os corpos em suas potências de afecção.

\section{REFERÊNCIAS}

BARDET, Marie. A Filosofia da Dança: um encontro entre Dança e Filosofia. São Paulo, Martins Fontes: 2014.

ELIAS, Andrea Nascimento. Fio de Ariadne: caminho para a construção de uma dramaturgia corporal a partir do espetáculo Cnossos. 2008. 210 f. Dissertação (Mestrado em Teatro) - Centro de Letras e Artes, Universidade Federal do Estado do Rio de Janeiro, Rio de Janeiro.

FOUCAULT, Michel. A ética do cuidado de si como prática de liberdade. In: FOUCAULT, Michel. Ditos e Escritos V - Ética, Sexualidade, Política. Rio de Janeiro: Forense Universitária, 2004.

GODARD, Hubert e KUYPERS, Patricia. Buracos negros - uma entrevista com Hubert Godard. In: O Percevejo online, Dossiê Corpo Cênico. Rio de Janeiro, vol. 2, $\mathrm{n}^{\circ}$ 2, PPGAC/UNIRIO, 2010 [2006].

Revista Interinstitucional Artes de Educar. Rio de Janeiro, V. 6, N.2- pág. 748-764 maio-agosto de 2020: "Bebês e crianças: cultura, linguagem e políticas" 
IKEOKA, Tânia Tiemi. Travessias ético-políticas: estudos em atuação com a Cia de Dança Teatro Xirê, com a Tribo de Atuadores Ói Nóis Aqui Traveiz e com o Grupo de Estudo Contorno de Ações. 2016. 191 f. Dissertação (Mestrado em Artes Cênicas) - Centro de Letras e Artes, Universidade Federal do Estado do Rio de Janeiro, Rio de Janeiro.

LARROSA, Jorge. Tremores: escritos sobre experiência. Belo Horizonte: Autêntica, 2017.

LIMA, Carla Andrea. Da Questão do Corpo ao Corpo em Questão. In: O Percevejo Online. Rio de Janeiro, vol. 06 | Número 01 | Janeiro-Junho/2014 | p. 152-165

Disponível em: http://www.seer.unirio.br/index.php/opercevejoonline/article/view/4867/4425

LOUPPE, Laurence. Poética da Dança Contemporânea. Lisboa, Orfeu Negro: 2012.

MÉSZAROS, István. A Educação para Além do Capital. São Paulo: Boitempo, 2008.

OIDA, Yoshi. O Ator Invisível. São Paulo: Beca, 2001.

PÉLBART, Peter Pal. Biopolítica. Sala Preta - Revista PPGAC USP, v. 7: 2007. Disponível em: https://www.revistas.usp.br/salapreta/article/view/57320/60302

ROLNIK, Sueli. Arte Cura? São Paulo: PUC-SP, 2003. Disponível em: http://www.pucsp.br/nucleodesubjetividade/Textos/SUELY/Hibrido.pdf

Geopolítica da Cafetinagem. In: eipcp - European Institute for Progressive Cultural Policies. Viena, 2006. Disponível em: http://eipcp.net/transversal/1106/rolnik/pt

Molda-se uma alma contemporânea: o vazio-pleno de Lygia Clark. In:The experimental Exercice of Freedom: Lygia Clark, Gego, Mathias Goeritz, Hélio Oiticica and Mira Schende. Los Angeles: The Museum of Contemporary Art, 1999. Disponível em: http://www.pucsp.br/nucleodesubjetividade/Textos/SUELY/Molda.pdf

SAFATLE, Vladimir. O Circuito dos Afetos: corpos políticos, desamparo e o fim do indivíduo. Belo Horizonte, Autêntica: 2016.

\footnotetext{
${ }^{\text {i }}$ Andrea Elias é coreógrafa, educadora, diretora, bailarina e atriz. Mestre em Teatro, Especialista em Educação Estética, Licenciada em Artes Cênicas, Doutoranda no Programa de Pós-Graduação em Artes Cênicas pela Universidade Federal do Estado do Rio de Janeiro/UNIRIO. Possui formação técnica em Dança pela Escola Angel Vianna de Estudo do Movimento e Artes e em Artes Circenses pela Escola Nacional de Circo. Em 2003 cria a Cia de Dança Teatro Xirê, com a qual desenvolve continuamente pesquisa, criação e produção de dança, predominantemente direcionada ao olhar de crianças. Rio de Janeiro/RJ. E-mail:andrea.nascimentoelias@ gmail.com Rio de Janeiro/RJ. ORCID: http://orcid.org/0000-0003-4697-9245

ii A Cia de Dança Teatro Xirê foi criada em 2003, no Rio de Janeiro, pela atriz e bailarina Andrea Elias. As investigações que deram origem à Cia tiveram início em 1998. Seus primeiros trabalhos resultaram em espetáculos de dança contemporânea para o público infanto juvenil, fazendo a Cia pioneira na produção em dança contemporânea para essa faixa etária no estado do Rio de Janeiro, produzindo continuamente desde sua criação. A Cia tem em seu repertório os espetáculos: "Ciranda" (2003), "Quando Crescer, Eu Quero Ser..." (2006), "Entrelace”
}

Revista Interinstitucional Artes de Educar. Rio de Janeiro, V. 6, N.2-pág. 748-764 maio-agosto de 2020: "Bebês e crianças: cultura, linguagem e politicas" 
(2011) e "Dingling" (2016), estes direcionados para crianças; "Esther Williams não quer mais nadar..." (2012) direcionado para adultos; e "Isto é sobre liberdade: o que você ainda lembra sobre ela?" (2016), performance para espaços públicos urbanos. Além dos espetáculos desenvolveu os projetos pedagógicos: "Pode Mexer!”, exposição interativa; e "Cadê a Dança?", material multilinguagem para fruição de dança contemporânea para crianças e educadores. Disponível em: https://ciaxire.com/principal/

\begin{abstract}
iii Antes da estreia de seu primeiro espetáculo foram empreendidos muitos encontros com públicos formados por crianças das mais diferenciadas faixas etárias e realidades sociais, acompanhadas ou não por pais ou responsáveis. Esta prática foi se tornando um procedimento da Cia ao longo de sua trajetória e, aos poucos, este período de experimentações foi sendo inserido nos cronogramas de trabalho como parte de seu procedimento de criação. Tais experimentações podiam consistir na mostra de um trecho do espetáculo, em uma performance que viria a ser realizada como experiência prévia à criação, ou mesmo em um workshop onde estariam sendo colocados as relações entre brincadeira, dança e a temática específica para cada criação. Essas experiências eram realizadas dentro de espaços escolares, em espaços públicos, em centros comunitários, centros culturais ou qualquer espaço que se abrisse para receber a proposta.
\end{abstract}

iv Segundo a conceituação da Abordagem Sistêmica do Gesto Expressivo, o gesto concreto se liga ao gesto prático, cotidiano, e dele origina o gesto dançado.

${ }^{\mathrm{V}}$ É notória a influência dos Vianna para o estudo das artes do corpo e do movimento. Sobre o pensamento e prática dos Vianna ver VIANNA, Klauss. A Dança. São Paulo, Siciliano: 1990; RAMOS, Enamar. Angel Vianna: a pedagoga do corpo. São Paulo: Summus, 2007; TEIXEIRA, Letícia Pereira. Inscrito em meu corpo: Uma abordagem reflexiva do trabalho corporal proposto por Angel Vianna. Dissertação de mestrado. Rio de Janeiro: Unirio, Programa de Pós graduação em Artes Cênicas, 2008; TAVARES, Joana Ribeiro da Silva. Klauss Vianna: do coreógrafo ao diretor. São Paulo: Annablume; Rio de Janeiro: Unirio, 2010.

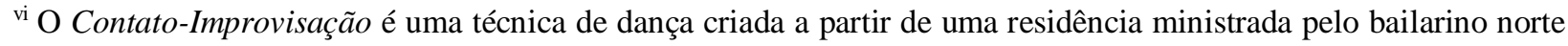
americano Steve Paxton na década de 70, num momento histórico em que os jovens americanos questionavam o autoritarismo e as guerras. A técnica propõe um diálogo perceptivo entre os corpos, por meio do contato e da troca de peso e energia. Os movimentos que daí surgem lidam com a inércia, com o momento, com o desequilíbrio e o inesperado.

vii Entrevistas realizadas com Tiago Quites, em 10 de abril de 2018; e com Luísa Pitta, em 14 de abril de 2018, para a pesquisa de doutoramento da autora, ainda em curso.

viii Saco Plástico Vazio consiste em um ou vários saquinhos de plástico vazios, que a artista dava para o cliente, geralmente no final da sessão, depois que lhe oferecera um Saco plástico cheio de ar para que ele o estourasse se assim o desejava. O cliente deveria encher o Saco Plástico Vazio com o ar de seu pulmão - o que, segundo a artista, lhe permitiria descobrir que o objeto destruído pode ser reposto e que, portanto, o processo de criação não se interrompe com a destruição do objeto (de arte?) (em ROLNIK, Suely. Breve Descrição dos Objetos Relacionais, p. 2 e 3). Disponível em: https://www.pucsp.br/nucleodesubjetividade/Textos/SUELY/descricaorelacionais.pdf Além de Saco Plástico Vazio, a obra Ovo Mortalha também na perspectiva do saco vazio, fez aproximação com a ideia de vazio que vamos perseguir. Nessa obra, de 1968, inscrita na série Arquiteturas Biológicas, num grande plástico transparente retangular, com sacos de náilon ou juta costurados em suas extremidades, pessoas enfiam os pés ou as mãos e passam a improvisar movimentos, cada uma envolvendo a outra no plástico (em ROLNIK, Suely. Molda-se uma alma contemporânea: o vazio-pleno de Lygia Clark, p. 16). Disponível em: https://www.pucsp.br/nucleodesubjetividade/Textos/SUELY/Molda.pdf

ix Performance em dança contemporânea da Cia de Dança Teatro Xirê, dirigida a crianças de 2 a 6 anos, com performance de Andrea Elias, direção de Norberto Presta, acompanhamento dramatúrgico de Anna-Lena Hode e música de Erich Hadke. O projeto foi desenvolvido em parceria entre a Cia Xirê e o Ladesbühne Niedersaxen Nord (Wilhemshaven - Alemanha), de outubro a dezembro de 2016 integrando a programação daquela temporada. Até o momento de escrita deste trabalho a obra ainda está inédita no Brasil depois de ter realizado mais de 60 apresentações na Alemanha. Disponível em: https://www.youtube.com/watch?v=KVB78yf21RY\&t=16s

Revista Interinstitucional Artes de Educar. Rio de Janeiro, V. 6, N.2- pág. 748-764 maio-agosto de 2020: "Bebês e crianças: cultura, linguagem e políticas"

DOI: 10.12957/riae.2020.46224 


\footnotetext{
${ }^{x}$ Corpo Vibrátil é um conceito desenvolvido por Sueli Rolnik que se refere a uma capacidade dos órgãos dos sentidos de apreender o mundo em sua condição de campo de forças que nos afetam e se manifestam no corpo sob a forma de sensações. O corpo vibrátil, portanto, é aquilo que em nós é ao mesmo tempo dentro e fora: o dentro nada mais sendo do que uma filtragem seletiva do fora operada pelo desejo, produzindo uma composição fugaz. Em ROLNIK, Sueli. Geopolítica da Cafetinagem. Disponível em: https://transversal.at/transversal/1106/rolnik/pt e Id, Molda-se uma alma Contemporânea. Nota 2 de fim de texto, p. 32.

xi Ovo Mortalha foi recriada para a exposição "Lygia Clark: uma retrospectiva”, realizada pelo Itaú Cultural, em São Paulo / 2012. Disponível em: https://www.youtube.com/watch?v=897UgvGH t8

${ }^{x i i}$ Sobre o trabalho com energia nas Artes Cênicas, referente ao corpo e ao movimento ver também ELIAS, 2008, p. 68 .

xiii Depois da experiência em Barcelona, o projeto foi realizado no Festival Panorama de Dança 2015 e contemplado pelo Fomento Rio Cidade Olímpica / Prefeitura da Cidade do Rio e Janeiro, realizando, de 20 a 27 de setembro de 2016, 20 intervenções urbanas percorrendo todas as áreas de planejamento do município. Sobre o projeto: https://istoesobreliberdade.wixsite.com/intervencaourbana
}

Revista Interinstitucional Artes de Educar. Rio de Janeiro, V. 6, N.2- pág. 748-764 maio-agosto de 2020: "Bebês e crianças: cultura, linguagem e políticas" 